\title{
O PORTAL DA TRANSPARÊNCIA COMO ESTRATÉGIA DE GOVERNANÇA PÚBLICA: A PERCEPÇÃO DOS GESTORES DA UFSM E DO IFFARROUPILHA
}

\author{
THE PORTFOLIO OF TRANSPARENCY AS A PUBLIC \\ GOVERNANCE STRATEGY: THE PERCEPTION OF THE \\ MANAGERS OF UFSM AND IFFARROUPILHA
}

Aline de Oliveira Botega

Decio Luis Schumacher

Nelson Guilherme Machado Pinto

RESUMO: Este artigo tem como objetivo identificar a percepção dos gestores de duas Instituições Federais de Ensino, a Universidade Federal de Santa Maria (UFSM) e o Instituto Federal Farroupilha, quanto ao uso do Portal da Transparência do Governo Federal como estratégia de gestão e governança pública. Para alcançar os objetivos propostos foi realizada uma breve revisão da literatura referente a temáticas de transparência e governança pública. A coleta de dados deu-se por meio de um questionário aplicado aos gestores ligados as Pró-Reitoras de Administração e Gestão de Pessoas das Instituições Federais de Ensino (IFES). A análise das informações foi orientada pela técnica qualitativa de análise de conteúdo. Percebe-se que ambas as instituições conhecem e reconhecem a importância do Portal da Transparência do Governo Federal no serviço público e como estratégia de governança pública, no entanto, essas informações têm o uso muito mais operacional do que estratégico.

palaVras-chaves: Portal da Transparência; Instituições Federais de Ensino; Governança Pública; Educação; Administração Pública.

ABSTRACT: This article aims to identify the perception of the managers of two Federal Educational Institutions, the Federal University of Santa Maria (UFSM) and the Federal Institute Farroupilha, regarding the use of the Transparency Portal of the Federal Government as a strategy for public management and governance. To achieve the proposed objectives, a brief review of the literature on transparency and public governance issues was carried out. The data collection was done through a questionnaire applied to the managers connected to the Pro-Rectors of Administration and Management of People of the Federal Institutions of Education (IFES). The analysis of the information was guided by the qualitative technique of content analysis. It is noticed that both institutions know and recognize the importance of the Federal Government's Transparency Portal in the public service and as a strategy of public governance, however, this information has a much more operational than a strategic use.

KEYwORDs: Transparency Portal; Federal Institutions of Education; Public Governance; Education; Public administration. 


\section{INTRODUÇÃO}

Em plena era da informação, com a predominância do uso das tecnologias da informação e comunicação, com a dinâmica e facilidade de acesso que a informação adquiriu, não é mais crível que o acesso a esta seja restrita a grupos privilegiados, principalmente no tocante aos atos da gestão pública, ao estabelecimento de políticas e aplicação dos recursos públicos. Num ambiente em que os recursos públicos são escassos e as demandas crescentes, é fundamental a otimização da alocação desses recursos e, uma das principais maneiras para que essa premissa venha a ser implementada é o controle social, via órgãos públicos de controle, como o poder legislativo em todas as esferas de governo, os respectivos tribunais de contas, dentre outros mecanismos existentes.

Nesse contexto, os sites e portais de transparência são, tanto em níveis federal, estadual e municipal, as mais importantes ferramentas disponíveis e acessíveis ao cidadão, para que este acompanhe e exerça seu papel de controle das políticas e da gestão pública. Como consequência, os portais de transparência, além da função de informar, visam aproximar o cidadão do Estado. De acordo com Rodrigues (2011,p.15), esta aproximação possibilita garantir ao cidadão "o acesso às informações financeiras sobre gestão do poder executivo. É em suma a abertura do que sempre se teve como mais sigiloso, as contas públicas, com fito de evitar a malversação do dinheiro público que desde os primórdios fora foco de inúmeras possibilidades de desvio e corrupção".

O Portal da Transparência do Governo Federal possui várias interfaces, fornecendo uma significativa gama de informações acessíveis ao cidadão. Essas informações vão desde a consulta aos valores pagos a todos os servidores do governo federal, até a possibilidade de acompanhamento dos programas, orçamentos e suas respectivas execuções e liquidações nos diversos ministérios, e secretarias do governo federal.

Diante desse contexto, e considerando a importância que a educação pública possui no Brasil, este artigo tem como objetivo principal efetuar um levantamento sobre a percepção dos gestores de duas Instituições Federais de Ensino (IFES), a Universidade Federal de Santa Maria (UFSM) e o Instituto Federal de Educação, Ciência e Tecnologia Farroupilha (IFFarroupilha) têm sobre a utilização do Portal da Transparência do Governo Federal como ferramenta de estratégia de governança pública. Nesse sentido, delimitou-se o ambiente desta pesquisa aos gestores das Pró-Reitorias de Administração e Gestão de Pessoas, por se entender que estas são as principais unidades das IFES no que se refere à execução dos recursos públicos, logo, setores em que existe uma maior demanda por transparência.

A fim de atingir esse objetivo, o presente artigo está estruturado, além desta introdução, em quatro seções. Na segunda seção, é apresentada a revisão de literatura; na seção seguinte, os procedimentos metodológicos utilizados; na quarta seção, os resultados são analisados 
e discutidos e, por último, são apresentadas as considerações finais do trabalho.

\section{REVISÃO DE LITERATURA}

\subsection{AS INSTITUIÇÕES FEDERAIS DE ENSINO - IFFARROUPILHA E UFSM}

As IFES caracterizam-se como instituições com natureza jurídica de autarquia, que lhes conferem autonomia administrativa, patrimonial, financeira, didático-pedagógica e disciplinar. $\mathrm{O}$ Instituto Federal de Educação, Ciência e Tecnologia Farroupilha (IFFarroupilha) foi criado pela Lei ${ }^{\circ} 11.892$, de 29 de dezembro de 2008, por meio da integração do Centro Federal de Educação Tecnológica de São Vicente do Sul, de sua Unidade Descentralizada de Júlio de Castilhos, da Escola Agrotécnica Federal de Alegrete, e do acréscimo da Unidade Descentralizada de Ensino de Santo Augusto que anteriormente pertencia ao Centro Federal de Educação Tecnológica de Bento Gonçalves (IF FARROUPILHA, 2014).

De acordo com a lei de sua criação, o IF Farroupilha é uma instituição de educação superior, básica e profissional, pluricurricular e multicampi, especializada na oferta de educação profissional e tecnológica nas diferentes modalidades de ensino. O IF Farroupilha, em atenção aos arranjos produtivos sociais e culturais locais, oferta cursos de formação inicial e continuada de trabalhadores, cursos técnicos de nível médio (presenciais e a distância) e cursos de graduação e pós-graduação, proporcionando a verticalização do ensino. Atualmente é composto por 11 unidades de ensino, campus, uma unidade administrativa, Reitoria, Polos de Educação a Distância e Centros de Referência (IF FARRoupilHa, 2014).

Já a UFSM é uma Instituição Federal de Ensino Superior constituída como Autarquia Especial vinculada ao Ministério da Educação. Foi fundada em 1960 pelo professor José Mariano da Rocha Filho, conta atualmente com dez unidades de ensino espalhadas pelo Rio Grande do Sul, além de quatro estabelecimentos de educação básica, técnica e tecnológica (UFSM, 2011).

A atual estrutura, determinada pelo Estatuto da Universidade, aprovado pela Portaria Ministerial n. 801, de 27 de abril de 2001, e publicado no Diário Oficial da União em 30 de abril do mesmo ano, estabelece a constituição de oito unidades universitárias: Centro de Ciências Naturais e Exatas, Centro de Ciências Rurais, Centro de Ciências da Saúde, Centro de Educação, Centro de Ciências Sociais e Humanas, Centro de Tecnologia, Centro de Artes e Letras e Centro de Educação Física e Desportos (UFSM, 2011).

Em 20 de julho de 2005, o Conselho Universitário aprovou a criação do Centro de Educação Superior Norte-RS/UFSM (CESNORS), passando a UFSM a contar com nove unidades universitárias. A instalação do CESNORS tem como objetivo impulsionar o desenvolvimento 
da região norte do estado do Rio Grande do Sul, visando à expansão da educação pública superior. Em 2015 o CESNORS foi elevado à condição de campus universitário de Palmeira das Missões e de Frederico Westphalen. Da estrutura da Universidade, fazem parte também duas escolas de ensino médio e tecnológico: Colégio Politécnico da Universidade Federal de Santa Maria, e o Colégio Técnico Industrial de Santa Maria (UFSM, 2011).

A UFSM está localizada no centro geográfico do estado do Rio Grande do Sul, distante $290 \mathrm{~km}$ de Porto Alegre. O município de Santa Maria é o pólo de uma importante região agropecuária que ocupa a parte centro-oeste do Estado. No município, formou-se um importante pólo de prestação de serviços com destaque para a educação em todos os níveis, tendo a UFSM um papel preponderante no desenvolvimento de Santa Maria (UFSM, 2011).

\subsection{TRANSPARÊNCIA PÚBLICA}

A transparência pública tem sido cada vez mais associada ao fortalecimento da democracia. Para Angélico (2012), a expressão "acesso à informação pública" corresponde à materialização do conceito de transparência pública.

A partir disso, o acesso público às informações é um instrumento de que as políticas governamentais não se encerram por si mesmos. Dessa forma, isso faz com que seja garantido a figura de um Estado transparente e responsável (GRUMAN, 2012).

Com a Reforma do Estado, percebe-se maior preocupação deste em aproximar-se dos cidadãos. E para isso, as tecnologias de informações e comunicação foram adotadas para promover mais agilidade e eficiência na prestação de serviços e informações governamentais. Diversos portais e sites foram desenvolvidos para ampla publicidade das informações de interesse público. Para a Controladoria Geral da União (CGU), "transparência é quando sabemos onde, como e por que o dinheiro está sendo gasto. É quando as coisas são feitas às claras, sem mistérios, como devem ser feitas. A administração pública deve ser sempre transparente, porque não deve ter o que esconder do povo" (BRASIL, 2009a, p. 27).

Nessa perspectiva, Castells (2003) afirma que em vez de o governo vigiar as pessoas, as pessoas poderiam estar vigiando o seu governo, o que é de fato direito delas. Nesse sentido, a CGU visando uma ferramenta de promoção da transparência e de estimulo à participação e controle social, criou em 2004, o Portal da Transparência do Governo Federal com o objetivo de aumentar a transparência da gestão pública, permitindo que o cidadão acompanhe como o dinheiro público está sendo utilizado e ajude a fiscalizar (BRASIL, 2016). 


\subsection{PORTAL DA TRANSPARÊNCIA DO GOVERNO FEDERAL}

O Portal da Transparência do Governo Federal foi criado em novembro de 2004 para viabilizar o acompanhamento, pelo gestor público e pelo cidadão, da execução financeira de todos os programas e ações do Governo Federal. Nele estão disponíveis informações sobre recursos transferidos pelo Governo Federal aos estados e municípios, no âmbito de programas ou convênios; recursos transferidos diretamente ao cidadão; gastos diretos, realizados pelo Governo Federal em compras ou contratação de obras e serviços, incluindo os gastos de cada órgão com diárias, material de expediente, compra de equipamentos e obras e serviços; bem como gastos realizados por meio de cartões de pagamentos do Governo Federal. Os dados divulgados no Portal da Transparência são de responsabilidade dos ministérios e outros órgãos do Poder Executivo Federal (BRAsIL, 2016).
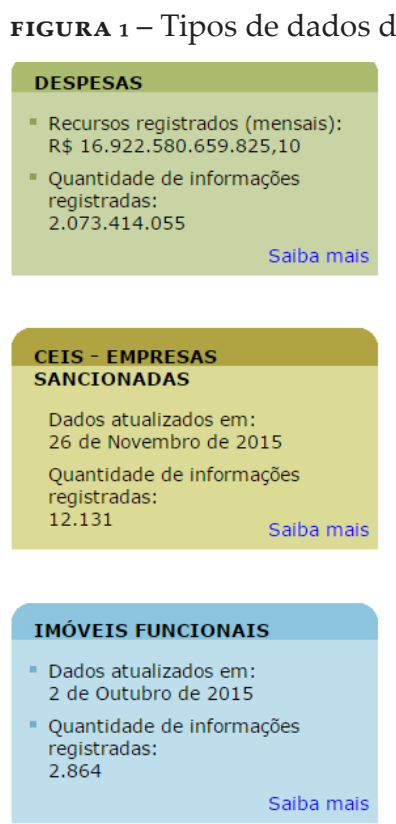
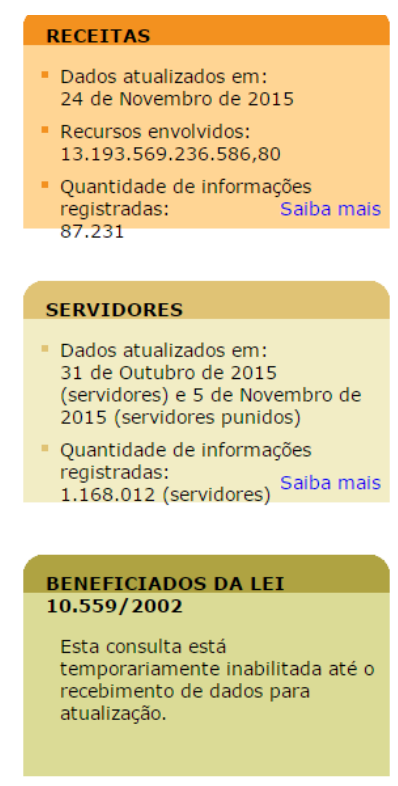
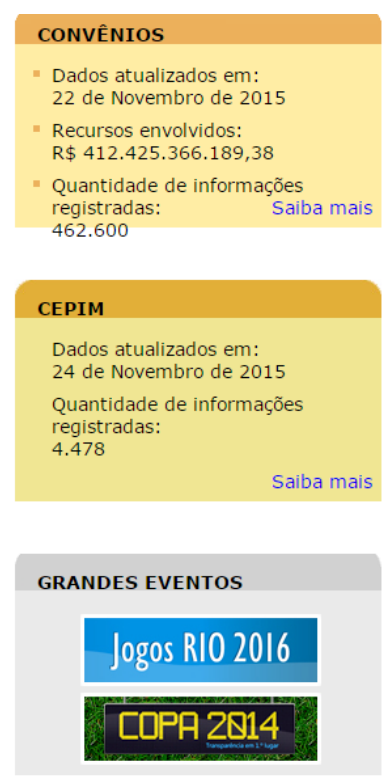

FONTE: Portal da Transparência

O Portal da Transparência é visto como uma ferramenta tecnológica de transparência pública. Seu principal público-alvo é o cidadão. O portal possibilita a este público acompanhar a aplicação dos recursos públicos e ainda, exercer o controle social. O portal atende também a outros públicos, como por exemplo, organizações não-governamentais, entidades privadas, gestores federais, estaduais e municipais (BRASIL, 2016).

Para Neves (2013, p. 6) "é visível que o escopo do Portal se ampliou, extrapolando a visão sobre o dinheiro público para uma visão sobre o emprego de recursos públicos." Além das informações sobre as despesas e receitas, o Portal informa também sobre imóveis funcionais, quadro de servidores, pessoas e organizações impedidas de fazerem 
A transparência pública, operacionalizada por meio do Portal da Transparência, de acordo com Freire (2014, p. 67) "funciona como um indutor para que os gestores públicos apliquem eficaz, eficiente e efetivamente o dinheiro público, pois o uso desses recursos está publicado e acessível a qualquer pessoa que acesse esse website." $\mathrm{O}$ Portal é um importante elemento de governança pública que propicia o controle da gestão pública pelos stakeholders, uma vez que possibilita a accountability.

\subsection{GOVERNANÇA PÚBLICA}

Nos últimos anos o tema governança, seja ela focada para empresas ou governos, está em voga, principalmente após a eclosão da crise imobiliária dos Estados Unidos em 2008 e a consequência crise econômica deste para todo o planeta. Daí a maior ênfase com a implantação e/ou difusão dos conceitos de governança tanto nas corporações quanto no setor público. Matias-Pereira (2010a, p.11) relata que "a governança coorporativa no setor público, refere-se à administração das agências do setor público, por meio dos princípios da governança coorporativa do setor privado"

Conforme Slomski et al. (2008), a governança prega a proteção ao inter-relacionamento entre a administração, o controle e a supervisão, visando relacionar os objetivos políticos eficiente e eficazmente, como, também, comunicar publicamente e providenciar uma prestação de contas para o benefício da sociedade. Afirmam que a governança no setor público inclui o modo como uma organização é administrada, a estrutura corporativa, a cultura, as políticas, as estratégias e a forma como a organização lida com os diversos stakeholders. Compreende, deste modo, a maneira como as organizações do setor público desempenham as responsabilidades que lhes são atribuídas, sendo transparentes, accountables e prudentes nas decisões, na elaboração de políticas e na execução dos programas.

Os princípios da governança pública, segundo a IFAC (2001), são a Transparência, a Integridade e a Responsabilidade, sendo esta última, a responsabilidade de prestar contas. Na visão de Santos et al. (2012) a determinação destes princípios auxilia a padronização da comunicação dos gestores públicos com a população, pois, com base nesses princípios, o ato de informar os resultados da gestão pública de forma concisa, objetiva e responsável denota a exigibilidade de qualquer usuário dos serviços públicos diante dos meios de informação disponíveis na atualidade.

O Portal da Transparência Federal, objeto desse estudo junto aos gestores da UFSM e do IF Farroupilha, preconizado pela Lei 131/2019 (Lei da Transparência), se traduz numa importante ferramenta de governança pública, visto que possibilita a aplicação prática do princípio da transparência e do accountability, propiciando acompanhamento contínuo da aplicação dos recursos e políticas dessas instituições pelos stakeholders. 


\section{PROCEDIMENTOS METODOLÓGICOS}

Para Gil (2002) é possível classificar as pesquisas em três grupos: exploratórias, descritivas e explicativas. Para atingir os objetivos desse estudo será utilizada a pesquisa de caráter descritivo com análise qualitativa, que tem como objetivo descrever as características de determinada população ou fenômeno, ou estabelecer relações entre variáveis.

O presente trabalho caracteriza-se como um estudo de caso. De acordo com Gil (2010), o estudo de caso é um estudo profundo que tem o foco em uma situação específica. Para a coleta de dados utilizou-se um questionário, encaminhado por e-mail, onde buscou-se identificar a percepção dos gestores das IFES quanto ao portal da transparência e quanto ao seu uso como uma estratégia de governança pública. A análise dos dados foi orientada pela técnica qualitativa de análise de conteúdo, conforme Vergara (2006) a técnica qualitativa visa identificar o que está sendo dito a respeito de determinado tema. E a análise de conteúdo possibilita que sejam agrupados elementos comuns na forma de categorias.

A pesquisa foi aplicada com gestores de cada uma das IFES, sendo eles lotados na Pró-Reitoria de Administração e na Pró-Reitoria de Gestão de Pessoas. Totalizando sete gestores que responderam a pesquisa, sendo quatro do IF Farroupilha e três da UFSM.

\section{RESULTADOS E DISCUSSÃO}

Através do questionário, foram feitas nove perguntas a servidores públicos da UFSM e do IF Farroupilha, ocupantes de cargos de gestão das Pró-Reitorias de Administração e Gestão de Pessoas. Para análise dos dados foram definidas seis categorias, descritas a seguir.

\subsection{MOTIVOS DE ACESSO}

Inicialmente buscou-se identificar a frequência e os motivos de acesso ao portal da transparência pelos gestores das IFES. Verificouse que não há assiduidade quanto ao acesso, e que este se dá principalmente para atender demandas pontuais de rotinas de trabalho. Conforme conclui o gestor atuante na área de Gestão de Pessoas do IF Farroupilha: "Objetivos específicos para atendimento de demandas de trabalho". Assim como um gestor da Pró-Reitoria de Administração da UFSM, "Pouco acesso, só quando necessário para informações da execução orçamentária, com objetivo de análise de dados."

\subsection{USOS DAS INFORMAÇÕES CONSTANTES NO PORTAL}

Quando se questionou qual o uso das informações constantes no portal da transparência pelos gestores, observou-se que em ambas as IFES o uso das informações são para atendimento de objetivos específicos de trabalho, como por exemplo, consulta a empenhos, liquidação e pagamento de fornecedores e algumas outras despesas. Conforme 
abordou uma gestora do IF Farroupilha, "Estas informações são úteis para acompanhar a execução da despesa da minha instituição." Diante das respostas conclui-se que falta uma visão mais estratégica do uso das informações constantes no portal da transparência pelos gestores das IFES.

\subsection{PORTAL DA TRANSPARÊNCIA DO GOVERNO FEDERAL COMO FERRAMENTA}

Identificou-se uma percepção positiva do portal da transparência pelos gestores das duas IFES. O termo portal da transparência como uma ferramenta "interessante" e "importante" foi repetida por diferentes gestores de ambas as instituições. "Considero uma ferramenta importantíssima para o controle e acompanhamento do gasto público", afirmou uma gestora da UFSM. A ressalva apontada foi com relação a dificuldade de compreensão de algumas informações pela população em geral, como bem resumiu uma gestora do IF Farroupilha "O portal publica várias informações importantes, mas para as pessoas que não tem conhecimento da administração pública, torna-se difícil compreender."

\subsection{QUALIDADE DAS INFORMAÇÕES}

Buscou-se identificar a percepção dos gestores quanto à qualidade das informações constantes no portal. Todos os respondentes avaliaram positivamente, como bem pontua uma gestora da PróReitoria de Administração da UFSM: "As informações são confiáveis e demonstram a transparência do gasto público." No entanto, os gestores das duas IFES concordam que a linguagem utilizada não é de fácil compreensão ao cidadão. "As informações sobre pessoal são de fácil compreensão, contudo as que se referem a gastos dos órgãos públicos podem causar confusões relativas a determinadas terminologias."

\subsection{GOVERNANÇA PÚBLICA}

Foi questionado aos gestores o que seria governança pública. Surgiram termos como "melhor transparência dos atos públicos dos gestores e melhoria na eficácia do gasto público"; "utilização adequada de recursos e estratégias que possibilitem o alcance dos objetivos estatais"; "mecanismo para diminuir o distanciamento entre Estado e sociedade"; "ferramenta de gestão que visa o planejamento, o controle, a transparência do gasto público para atender melhor a sociedade"; "gasto eficaz e responsável dos gestores públicos". Diante disso, conclui-se que os gestores de ambas as IFES têm o conhecimento dos conceitos de governança pública no âmbito de suas instituições. 


\subsection{O PORTAL DA TRANSPARÊNCIA COMO \\ ESTRATÉGICA DE GOVERNANÇA PÚBLICA}

Quando se abordou a questão referente ao portal da transparência como estratégia de governança pública, surgiu novamente como destaque nas respostas o termo transparência pública. Todos os respondentes concordam e acreditam que o portal da transparência pode ser uma estratégia de governança pública. De acordo com uma gestora da UFSM: "Um dos princípios da Administração Pública é a transparência, que deve ser incorporada como uma estratégia de governo proporcionar à sociedade uma maior segurança de como está sendo gasto os recursos públicos. Ao ser traduzido em estratégia, o portal da transparência possibilita a aferição do princípio da eficiência."

\section{CONSIDERAÇÕES FINAIS}

Sem dúvida vivencia-se um momento ímpar de relação entre Estado e sociedade. A sociedade vem adquirindo, cada vez mais, consciência de seus direitos e deveres, e dessa forma sentindo-se mais participativa, crítica e responsável pelos seus atos e pelos atos de seus governantes. Nesse sentido, surgem os conceitos e discussões sobre governança no setor público. Assim, o portal da transparência do governo federal surge como uma ferramenta tecnológica de transparência pública que possibilita ao cidadão exercer o controle social.

Com a pesquisa realizada juntos aos gestores da UFSM e do IF Farroupilha foi possível perceber não haver distinção de conhecimento, percepção e até mesmo do uso do Portal Transparência do Governo Federal entre as duas IFES. Acredita-se que isso se deve principalmente ao fato do portal ser uma ferramenta relativamente nova no serviço público.

O Portal da Transparência é uma ferramenta conhecida e reconhecida pelos gestores das IFES, no entanto o uso desta é operacional, mais especificamente para consultas pontuais e atendimentos de rotina de trabalho. Os respondentes reconhecem o Portal da Transparência como uma estratégia de governança pública, intuindo o que significa governança, mas não utilizam desta ferramenta para auxiliar na gestão estratégica das IFES.

Por fim, constata-se que ambas as IFES pesquisadas dispõem de uma importante ferramenta de governança pública acessível a todos os seus stakeholders, que é o Portal da Transparência do Governo Federal, porém, falta-lhes uma percepção mais estratégica desta. E ainda, constatou-se que as percepções e usos do portal são semelhantes pelos gestores das duas IFES, apesar de serem instituições com tempo de existência bem distintos.A principal limitação do estudo foi a ausência de retorno dos questionários pela totalidade dos gestores das PróReitorias alvo da pesquisa. Para trabalhos futuros, sugere-se explorar mais o uso estratégico do Portal da Transparência pelas Instituições de Ensino, dos mais diversos níveis. 


\section{REFERÊNCIAS BIBLIOGRÁFICAS}

ANGÉLICO, F. Lei de Acesso à Informação Pública e seus possíveis desdobramentos à accountability democrática no Brasil. 2012. 132 f. Dissertação (Mestrado em Administração Pública e Governo) - Escola de Administração de Empresas de São Paulo, Fundação Getúlio Vargas, 2012. Disponível em: http://bibliotecadigital.fgv. br/dspace/handle/10438/9905. Acesso em 200ut2016.

BARDIN, L. Análise de Conteúdo. São Paulo: Edições 70, 2011.

BRASIL. Controladoria-Geral da União. Cartilha Olho Vivo no Dinheiro Público. $2^{\underline{a}}$ ed., maio, 2009a. Disponível em: http://www.cgu.gov.br/Publicacoes/controle-social/arquivos/ cartillhaolhovivo_baixa_v2.pdf Acesso em 200ut2016

$$
\text { CGU - CONTROLADORIA GERAL DA UNIÃO. }
$$

Portal da Transparência. Disponível em: < http://www. portaltransparencia.gov.br $>$, Acesso em 100ut2016

\section{Portal da Transparência do}

Governo Federal. Disponível em: < http://www. portaltransparencia.gov.br/>. Múltiplos acessos, 2016.

CASTELLS, Manuel. A galáxia da Internet: reflexões sobre a internet, os negócios e a sociedade. Trad. Maria Luiza X. de A. Borges. Rio de Janeiro: Jorge Zahar Ed. 2003.

FREIRE, Felipe Ribeiro. Desafios para a transparência pública: um estudo com usuários do Portal da Transparência do Governo Federal. 2014. 283 f. Dissertação (Mestrado em Ciência Política) - Universidade de Brasília, 2014. Disponível em: http:// repositorio.unb.br/handle/10482/17107. Acesso em 100ut2016

GIL, A. C. Como elaborar projetos de pesquisa. 5.ed. São Paulo: Atlas, 2010. Como elaborar projetos de

pesquisa. 4. ed. São Paulo: Atlas, 2002.

GRUMAN, M. Lei de Acesso à Informação: notas e um breve exemplo. Revista Debates, Porto Alegre, v. 6, n. 3, p. 97-108, set-dez, 2012.

IFAC, Governance in the Public Sector: A Governing Body Perspective International Public Sector - Study 13, IFAC, 2001.

IF FARROUPILHA. PLANO DE DESENVOLVIMENTO INSTITUCIONAL 2014-2018. Disponível em: http:// w2.iffarroupilha.edu.br/site/midias/arquivos/2015324151055989 pdi_14_18pdf.pdf. Múltiplos acessos, 2016. 


\section{MATIAS PEREIRA, José. Governança no}

Setor Público. São Paulo: Atlas, 2010

NEVES, O. Evolução das Políticas de Governo Aberto no Brasil. In: VI Congresso CONSAD, 16-18 abr. 2013, Brasília, Brasil. Anais. Brasília, CONSAD, 2013.

RODRIGUES, S.L. Mídia, Informação e Transparência:

Construindo a cidadania contra a corrupção no Maranhão. Trabalho apresentado no Grupo de Trabalho da II Conferência Sul-America e VII Conferência Brasileira da Mídia Cidadã, 2011.

SANTOS, Andresson Fernandes Araujo dos; VASCONCELOS, Marcos Túlio de Castro; LAGIOIA, Umbelina Cravo Teixeira; DEUS, Viviane Oliveira de. Estudo da percepção dos princípios de governança aplicado ao Setor público na gestão do plano de desenvolvimento da Educação superior pública brasileira, Reuni: um estudo na Universidade federal de Pernambuco. Registro Contábil, v. 3, n.2, p. 104-133, 2012

SLOMSKI, Valmor; MELLO, Gilmar Ribeiro de; TAVARES FILHO, Francisco; MACÊDO, Fabrício de Queiroz. Governança Corporativa e Governança da Gestão Pública. São Paulo: Atlas, 2008

UFSM. PLANO DE DESENVOLVIMENTO

INSTITUCIONAL 2011-2015. Disponível em: http://site. ufsm.br/arquivos/uploaded/arquivos/berebzeo-4629442e-b1af-79c251e3ac83.pdf Múltiplos acessos, 2016.

VERGARA, S. C. Métodos de pesquisa em administração. 2ed. São Paulo: Atlas, 2006

\section{ANEXO I}

PESQUISA SOBRE O PORTAL DA TRANSPARÊNCIA DO GOVERNO FEDERAL

As questões a seguir serão objeto para o artigo de conclusão da disciplina de Governança Pública do Mestrado Profissional em Gestão de Organização Públicas da UFSM e versa sobre o Portal da Transparência do Governo Federal.

O Portal da Transparência do Governo Federal é uma iniciativa da Controladoria-Geral da União (CGU), lançada em novembro de 2004, para assegurar a boa e correta aplicação dos recursos públicos. $\mathrm{O}$ objetivo é aumentar a transparência da gestão pública, permitindo que o cidadão acompanhe como o dinheiro público está sendo utilizado e ajude a fiscalizar. (www.portaltransparencia.gov.br/sobre/) 
Aline Botega e Décio Schumacher - Alunos especiais da Disciplina de Governança Pública do Mestrado Profissional em Gestão de Organizações Públicas da UFSM

Você acessa o Portal da Transparência do Governo Federal com frequência? Quais os motivos do acesso?

Qual a sua percepção sobre o portal da transparência do Governo Federal?

Você acredita que o portal atende ao objetivo proposto da sua criação? Por que?

Você trabalha com o portal da transparência, seja na alimentação ou no uso das informações constantes nele? Quais informações? Qual o uso dessas informações?

As informações constantes atendem os interesses dos usuários? São de fácil compreensão?

Qual a sua avaliação quanto a qualidade das informações constantes no portal da transparência do Governo Federal?

Para você o que é governança pública?

Você percebe o portal da transparência como estratégia de governança pública? Porque?

Para finalizar, quais melhorias você gostaria de sugerir para o Portal da Transparência do Governo Federal?

Qual o seu cargo ou função exercido na Instituição? 